\title{
Mycosporine-Like Amino Acids (MAAs) Profile of Two Marine Red Macroalgae, Gelidium sp. and Ceramium sp.
}

\author{
Abha Pandey, Shruti Pandey, Rajneesh, Jainendra Pathak, Haseen Ahmed, Vidya Singh \\ Shailendra P. Singh and Rajeshwar P. Sinha*
}

Laboratory of Photobiology and Molecular Microbiology, Centre of Advanced Study in Botany, Institute of Science, Banaras Hindu University, Varanasi-221005, India

\author{
*Corresponding author: Prof. Dr. Rajeshwar P. Sinha \\ Laboratory of Photobiology and Molecular Microbiology, Centre of Advanced Study in Botany, Institute of Science, Banaras Hindu \\ University, Varanasi-221005, India \\ emails: rpsinhabhu@gmail.com; r.p.sinha@gmx.net \\ Tel.: +91 542 2307147; Fax: +91 5422366402
}

\begin{abstract}
Macroalgae have evolved different strategies to mitigate the damaging effects of solar ultraviolet radiation (UVR), including accumulation of photoprotective compounds such as mycosporine-like amino acids (MAAs). MAAs are secondary metabolites, synthesized by a large variety of organisms including macroalgae, phytoplanktons, cyanobacteria, lichen, fungi and some marine animals. MAAs act as photoprotectants and antioxidants. In the present investigation, MAAs profile of methanolic extracts of two marine red algae Gelidium sp. and Ceramium sp., collected from their natural environment, was studied. High-performance liquid chromatography (HPLC) and UV-Vis spectrometry analyses were used to reveal different MAAs profile in the extracts obtained from these two red algae. The MAAs isolated by HPLC were identified as shinorine $\left(\lambda_{\max }=333.5 \mathrm{~nm}\right)$, porphyra-334 $\left(\lambda_{\max }=332.3 \mathrm{~nm}\right)$ and palythine $\left(\lambda_{\max }=317.9 \mathrm{~nm}\right)$ having retention times $(\mathrm{RT}) 1.26,2.12$ and 3.64 min, respectively, in the extract obtained from Gelidium sp. Similarly, shinorine $\left(\lambda_{\max }=332.3 \mathrm{~nm}\right)$, porphyra-334 $\left(\lambda_{\max }=333.5 \mathrm{~nm}\right)$ and palythinol $\left(\lambda_{\max }=332.5 \mathrm{~nm}\right)$ with RT 1.27, 2.13 and $4.61 \mathrm{~min}$, respectively, were identified in the extract obtained from Ceramium sp. This study revealed that Gelidium sp. and Ceramium sp. could serve as potential source for economical exploration of MAAs in pharmaceutical sciences.
\end{abstract}

Keywords: Gelidium; Ceramium; Mycosporine-like amino acids; Shinorine; Porphyra-334; UVR.

Abbreviations: HPLC: High-performance liquid chromatography; MAAs: Mycosporine-like amino acids; UVR: Ultraviolet radiation; UVA: Ultraviolet-A; UV-B: Ultraviolet-B, AS: Asterina-330, MG: Mycosporine-glycine, PE: Palythene, PL: Palythinol, PR: Porphyra-334, PT: Palythine, SH: Shinorine

\section{Introduction}

The continuous accumulation of anthropogenically released atmospheric pollutants, such as chlorofluorocarbons (CFCs), chlorocarbons (CCs), organobromides (OBs) and reactive nitrogen species (RNS) including nitric oxide (NO), nitrous oxide $\left(\mathrm{N}_{2} \mathrm{O}\right)$ and peroxynitrite (ONOO) in the stratosphere has resulted in the depletion of ozone layer which provides shield against ultraviolet radiation (UVR; 100-400 nm) (Crutzen, 1992; Lubin and Jensen, 1995; Ravishankara et al., 2009). The process of ozone depletion has been reported at mid latitude and especially in the Antarctic where ozone levels declined by more than $70 \%$ during late winter and early spring in the polar vortex (Smith et al., 1992). The decreased density of ozone layer results in increased intensity of harmful ultraviolet-B radiation (UV-B; 280$315 \mathrm{~nm}$ ) reaching on the Earth's surface (Hofmann and Deshler, 1991; Madronich et al., 1998; Sahoo et al., 2005). UV-B radiation fluence reaching temperate and equatorial latitudes could be $1.5-2 \mathrm{Wm}^{-2}$, as compared with $50-60$ $\mathrm{Wm}^{-2}$ of ultraviolet-A radiation (UV-A; $315-400 \mathrm{~nm}$ ) and $500 \mathrm{Wm}^{-2}$ of photosynthetically active radiation (PAR; 400-700 nm) under clear weather conditions (Castenholz, 1997).

Although very small proportion of UV-B radiation reaches on the Earth (< $1 \%$ of total irradiance), it is highly energetic and has the potential to affect all living 
organisms by damaging a number of physiological, biochemical and molecular processes (Gao et al., 2007; Lesser, 2008; Sinha et al., 2008). Phototrophic organisms are especially prone to negative effects of UVR due to their obligation for harvesting light energy to produce chemical energy and reducing power for fixation of carbon. UVR may reach upto 70 meter into sea water column depending on the organic matter, flora and fauna of aquatic ecosystems, and can negatively affect the benthic photosynthesizers including cyanobacteria, phytoplankton and macroalgae (Smith et al., 1992; Häder et al., 2007). Thus, UVR has the potential to exert deleterious effects on photosynthetic terrestrial and aquatic organisms, thereby affecting the productivity of ecosystems (Karentz et al., 1991a; Vincent and Roy, 1993; Williamson, 1995; Sinha and Häder, 1996).

UVR can directly affect macromolecules such as DNA and proteins whereas indirect damages are caused due to production of reactive oxygen species (ROS) (Karentz et al., 1991b; Vincent and Neale, 2000). However, many photosynthetic microorganisms have developed certain mitigation strategies such as avoidance, scavenging of UVinduced ROS by enzymatic and non-enzymatic antioxidants (Middleton and Teramura, 1994; Singh et al., 2013), and screening by certain UV-absorbing/screening compounds like MAAs and scytonemin that counteract the deleterious effects of UVR (Karentz et al., 1991c; Dunlap and Shick, 1998; Sinha et al., 1998). Besides this, repair of UV-induced damage of DNA by photoreactivation and excision repair and resynthesis of proteins are also important mechanisms to prevent UV-induced photodamage (Britt, 1995; Kim and Sancar, 1995).

In this context, MAAs have obtained much consideration for their photoprotective role as these compounds have been reported in cyanobacteria, macroalgae, phytoplankton and various marine animals such as arthropods, rotifers, molluscs, fishes, cnidarians, tunicates, poriferans, nemertineans, echinodermates, platyhelminthes, polychaetes, bryozoans and protozoans (Sinha et al., 2007). This also indicates the evolutionary significance of these compounds during the course of evolution by conserving them. It has been found that MAAs provides protection from UVR not only in their producers but also to primary and secondary consumers through the food chain (Helbling et al., 2002). MAAs are small (<400 Da), colorless, water-soluble compounds composed of a cyclohexenone or cyclohexenimine chromophore conjugated with the nitrogen substituent of an amino acids or its imino alcohol (Singh et al., 2008; Richa and Sinha, 2015). Generally, the ring system contains a glycine subunit at the third carbon atom. Some MAAs also contains sulfate esters or glycosidic linkages through the imine substituent (Böhm et al., 1995; Wu et al., 1997).
The strong UV-absorption maxima of MAAs between 310 and $362 \mathrm{~nm}$ (Cockell and Knowland, 1999), their high molar extinction coefficients $\left(\varepsilon=28,100-50,000 \mathrm{M}^{-1}\right.$ $\mathrm{cm}^{-1}$ ) and photostability in both fresh and sea water in the presence of photosensitizers support the hypothesis that MAAs have a photoprotective role (Whitehead and Hedges, 2005). Differences in the absorption spectra of MAAs are due to variations in the attached side groups and nitrogen substituent. They are present intracellularly in many marine and freshwater organisms (Bandaranayake, 1998; Gröniger et al., 2000; Shick and Dunlap, 2002; Rezanka et al., 2004). UV exposure is essential for biosynthesis of MAAs, but some studies have suggested that other factors, including osmotic stress may also be involved in regulation of MAAs synthesis (Portwich and Garcia-Pichel, 1999).

In the cyanobacterium, Cylindrospermum stagnale sp. PCC 7417, a new gene cluster (mylA-E) putatively responsible for MAAs biosynthesis has been reported which is homologous to MAAs gene clusters from Anabaena variabilis sp. ATCC 29413 (ava_3855-3858) and Nostoc punctiforme (NpR5598-5600 and NpF5597) (Katoch et al., 2016). The two main enzymes involved in MAAs biosynthesis are $O$-methyltransferase $(O$-MT) encoded by genes Ava_3857, NpR5599, Myl B and 2demethyl-4-deoxygadusol (DDG) synthase encoded by genes Ava_3858, NpR5600, Myl A, respectively. Heterologous expression of mylA-E in Escherichia coli resulted in the production of mycosporine-lysine and the novel compound mycosporine-ornithine (Katoch et al., 2016).

MAAs are true 'multipurpose' secondary metabolites and due to potent UV-screening and antioxidant properties, it has widespread cosmeceuticals and pharmaceutical applications (Carreto and Carignan, 2011). Besides UVphotoprotective activity, these compounds also act as osmoprotectants, and, probably, anti-desiccant (Oren and Gunde-Cimerman, 2007). To date, more than 35 MAAs have been reported from marine organisms such as cyanobacteria, algae, and vertebrate and invertebrate animals (Becker et al., 2016). MAAs are most abundant in Rhodophyta (red algae) compared to Chlorophyta (green algae) and Phaeophyta (brown algae) macroalgal species (Karentz et al., 1991c; Hoyer et al., 2001; Kräbs et al., 2002; Sinha et al., 2007).

The red algae are one of the oldest groups of eukaryotic algae and also one of the largest, with about 5,000-6,000 species of mostly multicellular, macroscopic, marine algae, including many notable seaweeds. Their dominant pigment is phycoerythrin, which gives off rich shade of red color. Due to their sessile nature, macroalgae are exposed to elevated levels of PAR and UV radiation in their natural habitat. They cannot avoid radiation stress by migration to less affected areas like microalgae. The accumulation of 
MAAs has been previously reported for red algae as an effective strategy to counteract the damaging effects of UVR (Sinha et al., 2000). Some studies have reported synthesis and accumulation of various types of MAAs in Gelidium sp. and Ceramium sp. MAAs such as PT, AS and SH were found to be present in Gelidium amansii (Nakamura et al., 1982). Karsten et al. (1998a) showed presence of various MAAs in different species of Gelidium. AS, PT, PL, PR and SH were found to be present in Gelidium sp. (Karsten et al., 1998a). MAAs such as PT, AS, PL, PR and SH were reported in Gelidium pusillium and PT, AS, PL, PR and SH were screened in Gelidium sesquipedale (Karsten et al., 1998a). Gröniger et al. (2000) reported presence of SH in Gelidium latifolium. Similarly Karsten et al. (1998) reported various MAAs in different species of Ceramium. MG, PT, PL, PR and SH were found in Ceramium sp., PT, PR and SH were screened in Ceramium nodulosum and $\mathrm{MG}$ and $\mathrm{SH}$ were reported in Ceramium rubrum (Karsten et al., 1998a). As bioprospection and screening of MAAs constitute important aspect of its economic utility, the prime objective of the present study was to identify the MAAs present in two marine red macroalgae Gelidium sp. and
Ceramium sp. collected from Western coast (Arabian sea) of India.

\section{Materials and Methods}

\section{Geographical Region and Collection of Algal Material}

The two marine macroalgae belonging to the division Rhodophyta namely Gelidium sp. (Class Rhodophyceae, Order Gelidiales, Family Gelidiaceae) and Ceramium sp. (Class Rhodophyceae, Order Ceramiales, Family Ceramiaceae) were collected from their natural habitat, i.e., the rocky sea shore of Arabian sea near sunset point at Dwarka beach $\left(22^{\circ} 23^{\prime} \mathrm{N}, 68^{\circ} 97^{\prime} \mathrm{E}\right)$, Gujarat, India (Fig. $\mathbf{1 a}, \mathbf{b})$. Gelidium sp. is a thalloid red alga reaching around 0.79-16 inches in size. Species of Gelidium are found both in littoral region and in deeper water. Branching is irregular or occurs in rows on either side of the main stem (Fig. 1c). Similarly, Ceramium sp. is reddish brown in colour, prostrate and branched with terminal pincer-like structures at the end of each of the branches. Species of Ceramium occur abundantly between tide-level, as well as in deeper water. Ceramium sp. grows up to 10 inches in size (Fritsch, 1945) (Fig. 1d).

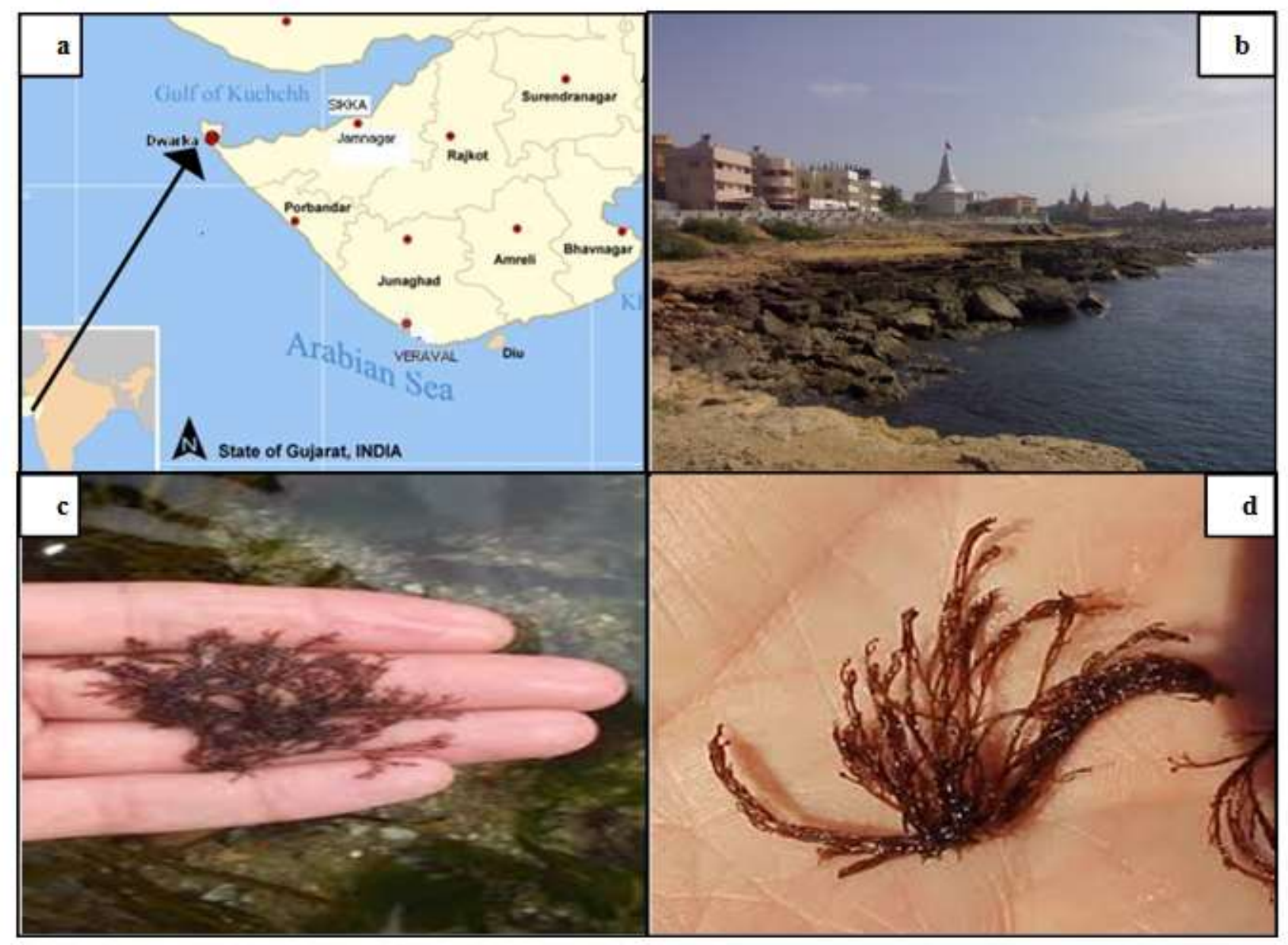

Fig. 1: Photographs showing (a) Map of sampling area, (b) Sunset point at Dwarka, Gujarat, India (collection site) (c) Morphology of Gelidium sp., and (d) Morphology of Ceramium sp. 


\section{Extraction and Partial Purification of Mycosporine-Like Amino Acids (MAAs)}

Extraction and partial purification of MAAs was done from weighed samples following the method of Sinha et al. (1999). The samples were homogenized in $5 \mathrm{ml} 100 \%$ methanol (HPLC grade, SRL Chem, New Mumbai, India) with the help of mortar and pestle and incubated overnight at $4^{\circ} \mathrm{C}$. After extraction, aliquots were centrifuged $(5000 \mathrm{~g}$ for $10 \mathrm{~min}$ ), and methanolic extracts were subjected to spectroscopic analysis between $200-700 \mathrm{~nm}$ in a UV-Vis double beam spectrophotometer (U-2910, 2J1-0012, Hitachi, Tokyo, Japan). The raw spectra were transferred to computer and peaks were analyzed by UV-solution software (Version-2.2, Hitachi, Tokyo, Japan). After scanning the methanolic extracts, supernatants were evaporated to dryness at $40^{\circ} \mathrm{C}$, and the extracts were redissolved in $2 \mathrm{ml}$ double distilled water. After centrifugation at $10000 \mathrm{~g}$ for $10 \mathrm{~min}$, aqueous solution was filtered through a sterilized syringe driven filter $(0.2 \mu \mathrm{m}$; Axiva Biotech., New Delhi), and transferred to new Eppendorf tubes. The partially purified MAAs were further subjected to HPLC analysis.

\section{High Performance Liquid Chromatography Analysis}

The partially purified MAAs were analyzed by HPLC system (Water 2998 with PDA detector, 515 PUMP, autoinjector 717 plus, Milford, USA) equipped with Empower-2 software. The system has an ODS-2 (RP18) column (Water, Spherisorb analytical column, $5 \mu \mathrm{m}, 4.6 \times$ $250 \mathrm{~mm}$ diameter, Ireland $)$ fitted with guard $(4.6 \times 10$ $\mathrm{mm})$. A $50 \mu \mathrm{l}$ sample was injected into the column and separation of MAAs was achieved by using $0.02 \%$ acetic acid as mobile phase with a flow rate of $1 \mathrm{ml} \mathrm{min}$. The identification of MAAs were performed as described earlier (Sinha et al., 1999, Kannaujiya et al., 2014).

\section{Results}

The present study investigated the presence of photoprotective compound, i.e., MAAs in two red algae Gelidium sp. and Ceramium sp. by spectroscopic analysis. Once the presence was confirmed, MAAs were further characterized by HPLC analysis based on the similarity of retention times (RT) and absorption spectrum of individual MAA with known standards.

\section{Spectroscopic Analysis}

The absorption spectra of methanolic extracts of both red algae showed a peak between 300-350 nm, which suggested the presence of MAAs in these organisms. The absorption maxima for MAAs were found to be at $320 \mathrm{~nm}$ and $332 \mathrm{~nm}$ for Gelidium sp. and Ceramium sp., respectively. In addition to the peaks for MAAs, methanolic extracts of Gelidium sp. and Ceramium sp. also showed the peaks for chlorophyll $a(420$ and $660 \mathrm{~nm})$, carotenoids $(460 \mathrm{~nm})$ and phycobiliprotein $(620 \mathrm{~nm})$ (Fig. $2 a, b)$.
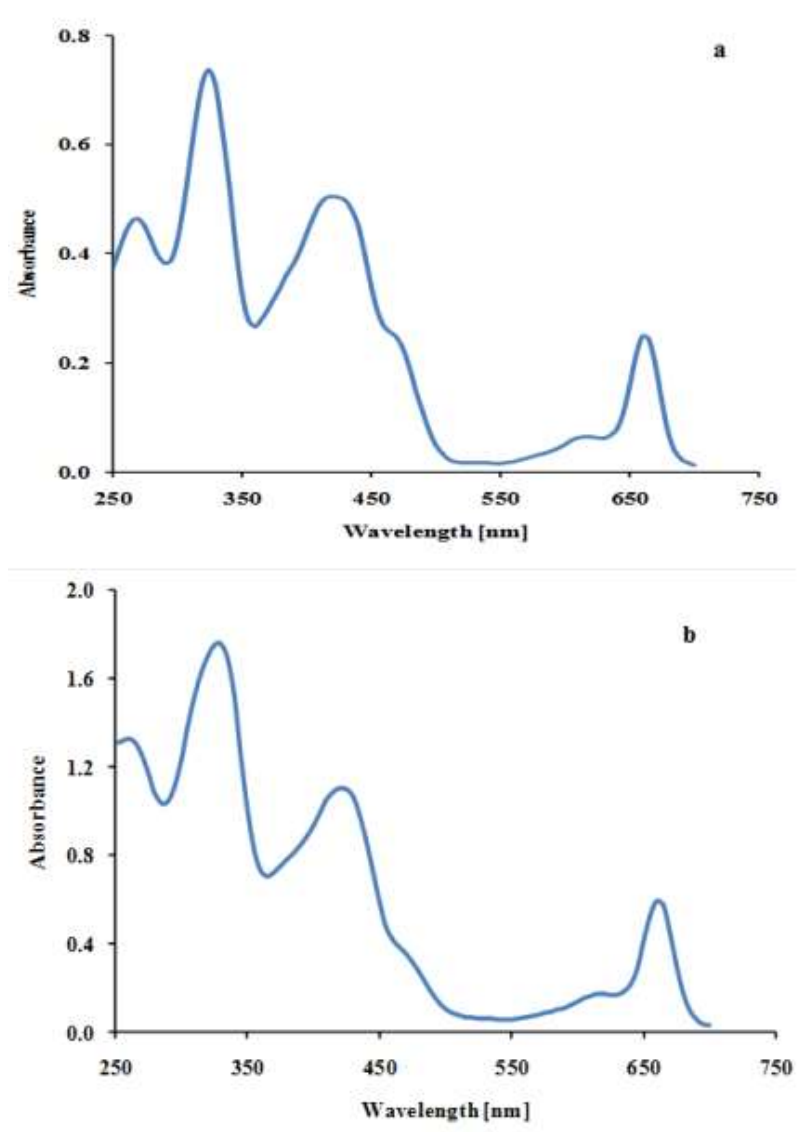

Fig. 2: Absorption spectra showing the presence of MAAs, chlorophyll $a$, carotenoids and biliproteins in (a) Gelidium sp. and (b) Ceramium sp.

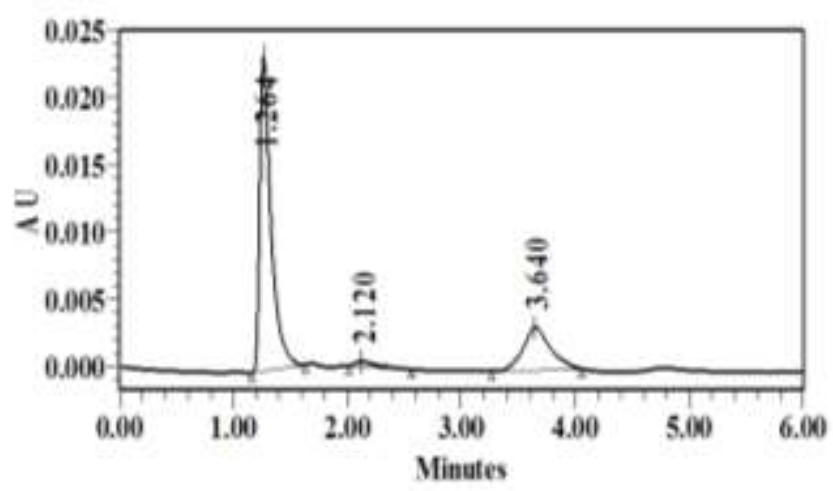

Fig. 3: HPLC chromatogram of partially purified MAAs from Gelidium sp., showing the typical peak at retention times of $1.26 \mathrm{~min}$ (shinorine), $2.12 \mathrm{~min}$ (porphyra-334), and 3.64 min (palythine).

\section{Separation and Identification of MAAs by High- Performance Liquid Chromatography (HPLC)}

The separated MAAs were identified based on the similarity of RT and absorption spectrum with standards. The chromatogram obtained from HPLC analysis confirmed the presence of three MAAs in Gelidium sp. (Fig. 3). Three MAAs in Gelidium sp. were identified as shinorine $\left(\lambda_{\max }=333.5 \mathrm{~nm}\right.$; Fig. $\left.4 \mathrm{a}\right)$, porphyra-334 $\left(\lambda_{\max }=\right.$ 332.3 nm; Fig. 4b) and palythine $\left(\lambda_{\max }=317.9\right.$ nm; Fig. 4c) 
with RT of $1.26,2.12$ and $3.64 \mathrm{~min}$, respectively. Similarly, aqueous solution of MAAs obtained from Ceramium sp. was found to contain three MAAs (Fig. 5) which were identified as shinorine $\left(\lambda_{\max }=332.3 \mathrm{~nm}\right.$; Fig. 6a), porphyra-334 $\left(\lambda_{\max }=333.5 \mathrm{~nm}\right.$; Fig. $\left.6 \mathrm{~b}\right)$ and palythinol $\left(\lambda_{\max }=332.5 \mathrm{~nm}\right.$; Fig. 6c) with RT of 1.27, 2.13 and 4.61 min, respectively.
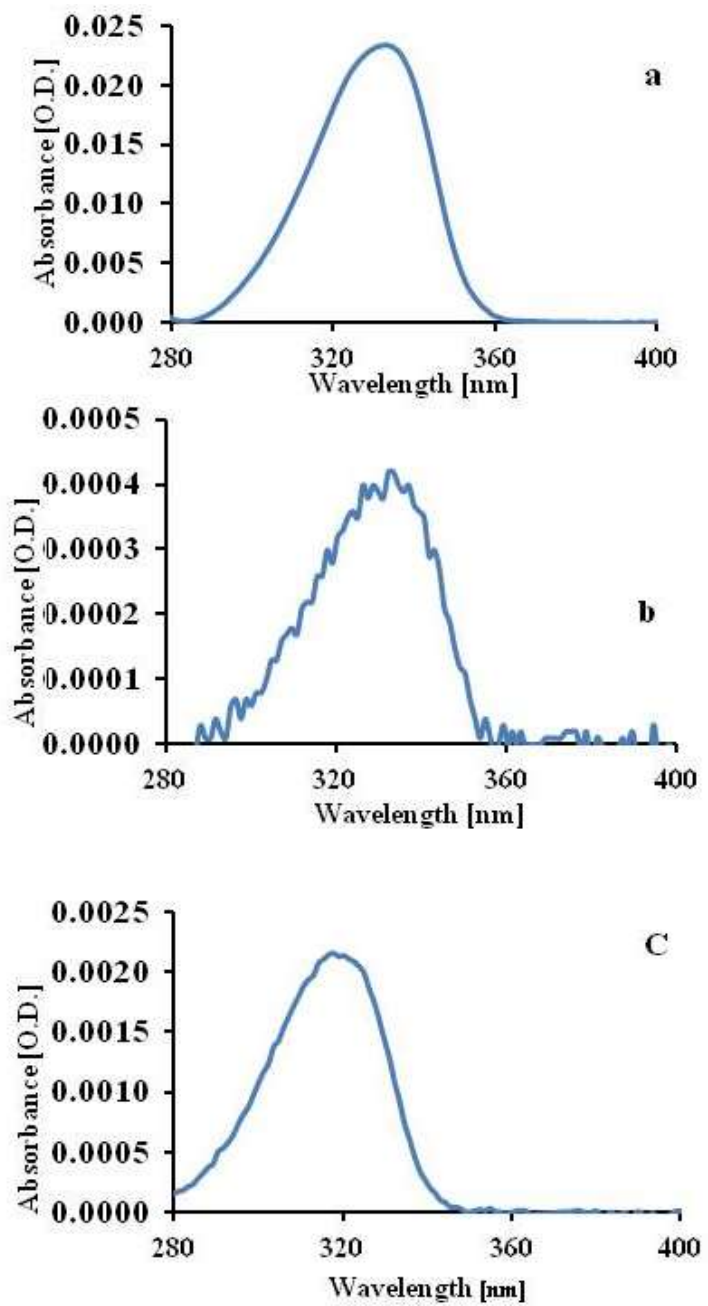

Fig. 4: Absorption spectra of purified MAAs from Gelidium sp. (a) shinorine, (b) porphyra-334 and (c) palythine, as separated by HPLC.

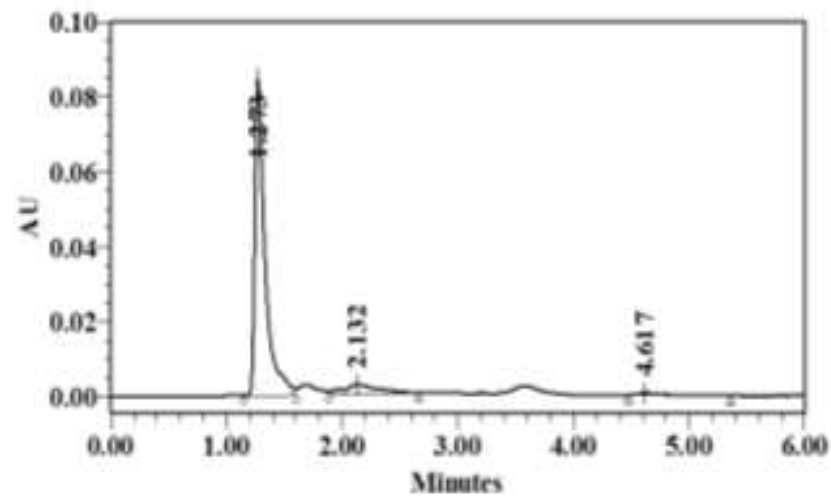

Fig. 5: HPLC chromatogram of partially purified MAAs from Ceramium sp., showing the typical peak at retention times of $1.27 \mathrm{~min}$ (shinorine), $2.13 \mathrm{~min}$ (porphyra-334), and $4.61 \mathrm{~min}$ (palythinol).
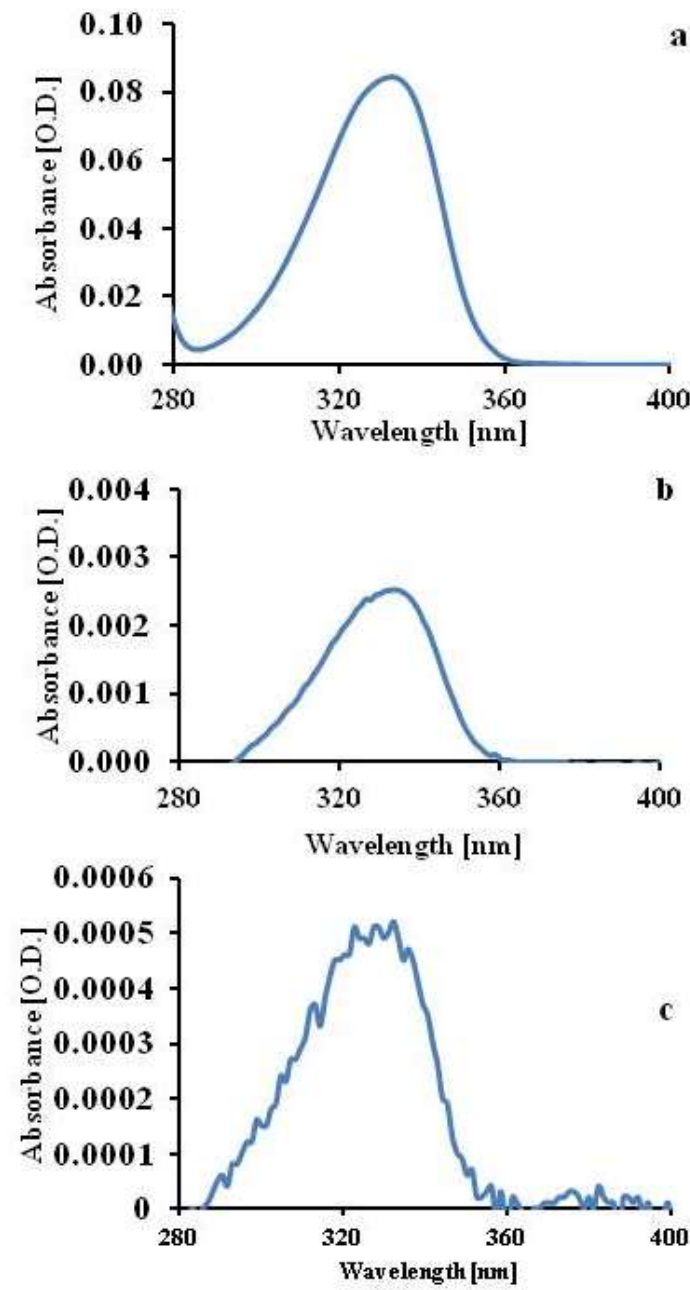

Fig. 6: Absorption spectra of purified mycosporine-like amino acids from Ceramium sp. (a) shinorine, (b) porphyra-334, and (c) palythinol, as separated by HPLC.

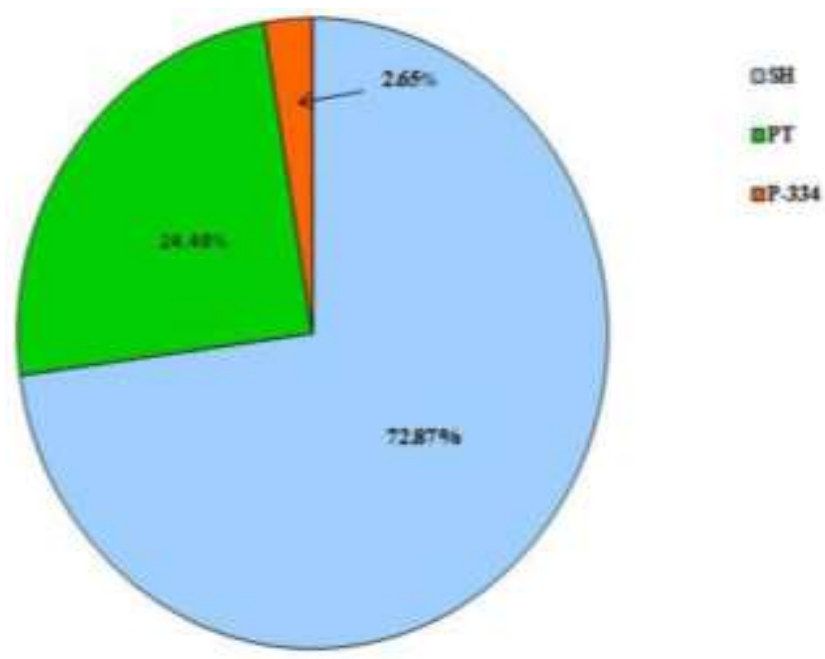

Fig. 7: Percentage distribution of MAAs (shinorine, palythine and porphyra-334) in Gelidium sp.

Once it became evident that these two red macroalgae produces MAAs, we calculated the percentage distribution of shinorine, porphyra-334 and palythine in Gelidium sp. and shinorine, porphyra-334 and palythinol in Ceramium 
sp., respectively. Fig. 7 represents the percentage distribution of MAAs in Gelidium sp. The results indicate that shinorine was contributing maximum (72.87\%) and porphyra-334 was contributing minimum $(2.65 \%)$ to the total MAAs in Gelidium sp. However, percentage distribution of palythine was found to be $24.48 \%$ to the total MAAs in Gelidium sp. Fig. 8 represents the percentage distribution of MAAs in Ceramium sp. with maximum contribution of shinorine (89.30\%) and minimum contribution of palythinol $(1.50 \%)$ to the total MAAs. Porphyra-334 was contributing $9.21 \%$ to the total MAAs in Ceramium sp. We quantified different MAAs in the two algal species in terms of the peak areas from their respective chromatograms as shown in Fig. 9 and Fig. 10.

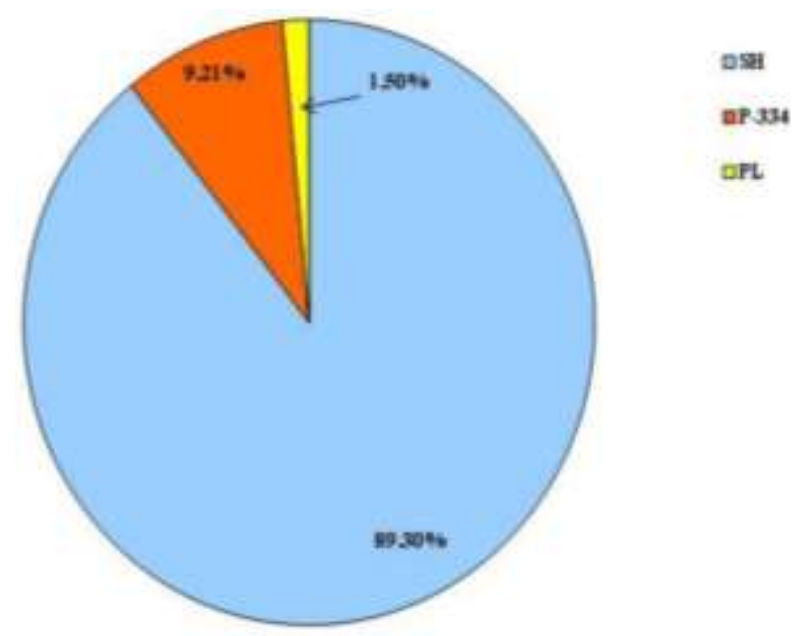

Fig. 8: Percentage distribution of MAAs (shinorine, porphyra-334 and palythinol) in Ceramium sp.

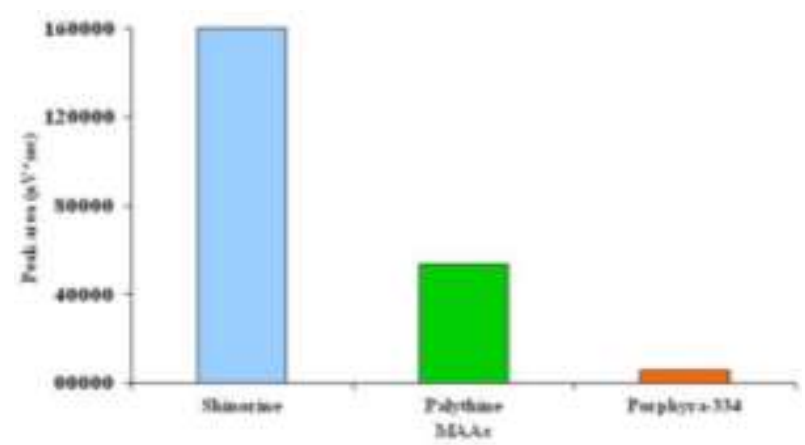

Fig. 9: Quantification of MAAs in Gelidium sp. in terms of peak area of chromatogram.

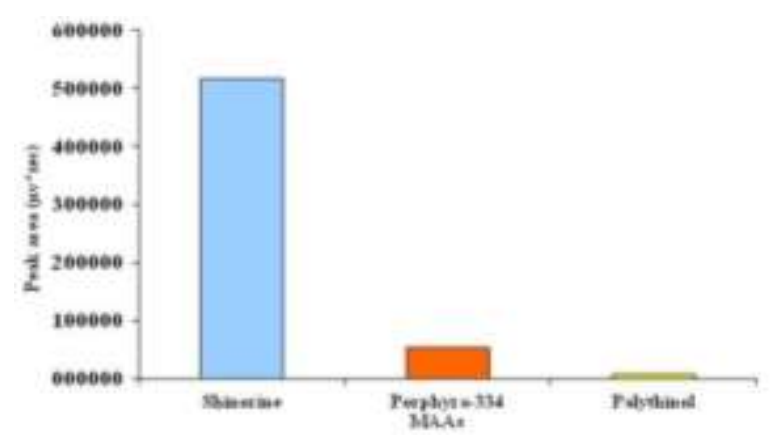

Fig. 10: Quantification of MAAs in Ceramium sp. in terms of peak area of chromatogram.

\section{Discussion}

Macroalgae, inhabiting the coastal areas of the world, are exposed to varying intensities of solar radiation, including harmful UV-B and UV-A radiation (Lüning, 1985). UV-B radiation is highly detrimental to all living organisms, including photosynthetic organisms inhabiting in marine, freshwater and terrestrial ecosystems. There is an evidence that UV-B irradiation results in the formation of thymine dimers in macroalgae such as Porphyra umbilicalis and Ceramium rubrum (= Ceramium virgatum), which results in several mutations in the genome of organisms (Sinha et al., 2001). UV-B radiation was found to induce mutation in tetraspores of the Rhodophyte Gracilariopsis lemaneiformis (Fu et al., 2013).

Phycobilisomes (PBSs), which are the major light harvesting complexes in red algae, were found to be sensitive to UVR (Schmidt et al., 2010a, b). Among different phycobiliproteins, phycocyanin was found to be most sensitive and it is rapidly destroyed by UV-B irradiation (Rinalducci et al., 2006). Thus, UVR negatively affects the process of carbon fixation which is reflected in terms of decreased photosynthetic efficiency. The passive screening of UVR by MAAs is one of the photoprotective mechanisms developed by several macroalgae against UVR (Sinha et al., 2007; Häder, 1997; Sinha et al., 1998, 2000; Carreto and Carignan, 2011; Kannaujiya et al. 2014; Richa et al., 2016). MAAs are known to absorb UVR and dissipate energy as harmless heat, and were estimated to prevent 3 out of 10 photons of UV-B radiation from hitting cytoplasmic targets in a cell (Garcia-Pichel et al., 1993).

The concentration of MAAs in macroalgae reflects the dose of UVR which is received in their natural habitats (Karsten et al., 1998b), and based on the levels of MAAs in various macroalgae, three patterns of MAAs distribution is commonly seen among macroalgae: (a) high initial MAA content and no increase during light treatment, (b) low MAA content with an increase during light treatment, and (c) no initial MAA and no induction during light treatment. However, in this study we did not test the induction of MAAs after light treatment due to limitation of the sample, and therefore, it is not possible to report the MAAs pattern for studied organisms. The red macroalga Chondrus crispus, harvested from the subtidal zone showed an increase in the number and amount of MAAs (Karsten et al., 1998b). Initial high levels but no significant increase in the MAAs content was found in the upper intertidal rhodophyte Porphyra umbilicalis (Gröniger et al., 1999). Similarly, no in vivo induction of MAAs was detected after exposure to either UV alone or in combination with PAR in the marine red alga Gracilaria cornea (= Hydropuntia cornea), which possesses a very high amount of naturally occurring MAAs having an absorption maximum at $334 \mathrm{~nm}$ (Sinha et al., 2000). Shinorine and porphyra-334 are the most 
common MAAs reported in macroalgae in species collected from tropical to polar waters (Karentz et al., 1991c; Karsten et al., 1998a; Helbling et al., 2004; Sinha et al., 2007), and in this study these two MAAs were also found in studied algae.

Recently, two novel MAAs named as catenelline and prasiolin were reported in marine red macroalgae Catenella repens and terrestrial green macroalga Prasiola calophylla, respectively (Hartmann et al., 2015, 16). A higher content of porphyra-334 in several red algae plays an important role in photoprotection (Conde et al., 2000). The algae of median tidal area are more efficient in producing UV-B screening compounds to cope up with its deleterious effect (Van De Poll et al., 2003). Algal extracts are valuable source of bioactive compounds such as antioxidants (polyphenols), tocopherols (vitamin E), ascorbate (vitamin C), glutathione (GSH), MAAs, pigments (carotenoids, chlorophylls, phycobilins, scytonemin), carbohydrates, proteins, lipids, minerals, and natural plant growth compounds (auxins, gibberellins, cytokinins) which possess antibacterial, antiviral, antifungal, antioxidative, anti-inflammatory, and antitumor properties and various potential of industrial applications (Rastogi and Sinha, 2009; Rajneesh et al., 2016).

MAAs are considered as natural photoprotectants that may be biotechnologically exploited in various ways. There is evidence that presence of MAAs (such as shinorine, porphyra-334 and mycosporine-glycine) protect human fibroblast cells from UV irradiation and it was observed that all the three examined MAAs protect the cells from UV-induced cell death (Oyamada et al., 2008). However, mycosporine-glycine was found to be more effective. MAAs has potential applications in cosmetics and toiletries as a UV protectors and activators of cell proliferation. MAAs have been commercially exploited as suncare products for protection of skin and other nonbiological materials, e.g., as photostabilising additives in plastics, paint and varnish (Bandaranayake, 1998).

A database has been developed on photoprotective compounds in micro- and macroalgae that can be responsible for the skin protection against solar UV radiation induced premature skin aging (photoaging). Different MAAs (mycosporine-glycine, palythine, asterina-330, palythinol, porphyra-334, shinorine, palythene) extracted from different species of macroalgae are listed in (Gröniger et al., 2000). A human study showed that a cream containing MAA from red alga Porphyra umbilicalis efficiently protects the skin against UVA-induced lipid oxidation (Schmid et al., 2006). A skin care product called Helioguard $® 365$ that contains MAAs from the red alga Porphyra umbilicalis has been commercialized. These compounds may be of great value in the development of artificial sunscreens and a source for future biotechnological research. Misonou et al. (2003) has observed that MAAs can block the production of both 6-4 photoproduct and cyclobutane pyrimidine dimer (CPD) formation. MAA extracted from red alga Porphyra umbilicalis demonstrated in in-vitro studies a DNAprotecting effect and the viability enhancing properties (Schmid et al., 2006).

MAAs may also act as antioxidants. For example, the oxocarbonyl mycosporines and porphyra-334 have antioxidant activity and prevent cellular damage resulting from UVinduced production of ROS (Carreto and Carignan, 2011). MAAs were extracted and purified from a marine red alga Bryocladia sp. (Kannaujiya et al., 2014). In vitro effects of hydrogen peroxide on algal MAAs with a view to illustrate their level of stability and scavenging properties against ROS were studied and it was found that isolated MAAs from Bryocladia sp. acted as an efficient peroxide scavenger (Kannaujiya et al., 2014). Antiproliferative activities of MAAs extracted from marine red macroalgae have studied. MAAs are suggested to exert pharmaceutical relevant bioactivities in the human system. Immunomodulatory effects of MAAs, shinorine and porphyra-334 have been investigated in human myelomocytic cell lines (Becker et al., 2016). The results from present investigation indicate that two types of MAAs shinorine and porphyra-334 could be present as photoprotective compounds in two marine red algae Gelidium sp. and Ceramium sp. Palythine and palythinol could only be present in Gelidium sp. and Ceramium sp. respectively in trace concentration.

\section{Acknowledgements}

A. Pandey, J. Pathak and V. Singh are thankful to Council of Scientific and Industrial Research, New Delhi, India, for providing funds in the form of fellowships. University Grant Commission, New Delhi, is thankfully acknowledged for providing fund in the form of fellowship to Haseen Ahmed. Rajneesh is thankful to Department of Biotechnology, Govt. of India, for providing grant in the form of a fellowship.

\section{Conflict of interest}

Authors declare no conflict of interest.

\section{References}

Bandaranayake WM (1998) Mycosporines: are they nature's sunscreens? Nat Prod Rep 15: 159-172. DOI: $\underline{10.1039 / \mathrm{a} 815159 \mathrm{y}}$

Becker K, Hartmann A, Ganzera M, Fuchs D and Gostner JM (2016) Immunomodulatory effects of the mycosporinelike amino acids shinorine and porphyra-334. Mar Drugs 14(6): 119-130. DOI: $10.3390 / \mathrm{md} 14060119$

Böhm GA, Pfleiderer W, Böger P and Scherer S (1995) Structure of a novel oligosaccharide-mycosporine-amino acid ultraviolet $\mathrm{A} / \mathrm{B}$ sunscreen pigment from the terrestrial 
cyanobacterium Nostoc commune. J Biol Chem 270(17): 8536-8539. DOI: $\underline{10.1074 / \mathrm{jbc} .270 .15 .8536}$

Britt AB (1995) Repair of DNA damage induced by ultraviolet radiation. Plant Physiol 108(3): 891-896. DOI: 10.1104/pp.108.3.891

Carreto JI and Carignan MO (2011) Mycosporine-like amino acids: relevant secondary metabolites. Chemical and ecological aspects. Mar Drugs 9(3): 387-446. DOI: $\underline{10.3390 / \mathrm{md} 9030387}$

Castenholz RW (1999) Multiple strategies for UV tolerance in cyanobacteria. Spectrum 10: 10-16.

Cockell CS and Knowland J (1999) Ultraviolet radiation screening compounds. Biol Rev 74: 311-345. DOI: 10.1017/S0006323199005356

Conde FR, Churio MS and Previtali CM (2000) The photoprotector mechanism of mycosporine-like amino acids. Excited-state properties and photostability of porphyra-334 in aqueous solution. $J$ Photochem Photobiol B 56: 139-144. DOI: $10.1016 /$ S10111344(00)00066-X

Crutzen PJ (1992) Ultraviolet on the increase. Nature 356:104105. DOI: $\underline{10.1038 / 356104 \mathrm{a} 0}$

Dunlap WC and Shick JM (1998) Ultraviolet radiation-absorbing mycosporine-like amino acids in coral reef organisms: a biochemical and environmental perspective. J Phycol 34: 418-430. DOI: 10.1046/j.1529-8817.1998.340418.x

Fritsch FE (1945) The structure and reproduction of the algae. Cambridge university press, London.

Fu F, Sui ZH, Zhou W, Wang JG, Chang LP and Ci SF (2013) UV-irradiation mutation of tetraspores of Gracilariopsis lemaneiformis and screening of thermotolerant strains. J Appl Phycol 26: 647-656. DOI: $10.1007 / \mathrm{s} 10811-013-0087-3$

Gao K, Yu H and Brown MT (2007) Solar PAR and UV radiation affects the physiology and morphology of the cyanobacterium Anabaena sp. PCC 7120. J Photochem Photobiol B 89: 117-124. DOI: 10.1016/j.jphotobiol.2007.09.006

Garcia-Pichel F, Wingard CE and Castenholz RW (1993) Evidence regarding the UV sunscreen role of a mycosporine-like compound in the cyanobacterium Gloeocapsa sp. Appl Environ Microbiol 59: 170-176.

Gröniger A, Hallier C and Häder D-P (1999) Influence of UV radiation and visible light on Porphyra umbilicalis: photoinhibition and MAA concentration. J Appl Phycol 11: 437-445. DOI: 10.1023/A:1008179322198

Gröniger A, Sinha RP, Klisch M and Häder D-P (2000) Photoprotective compounds in cyanobacteria, phytoplankton and macroalgae- a database. $J$ Photochem Photobiol $B$ 58: 115-122. DOI: $\underline{10.1016 / \mathrm{s} 1011-1344(00) 00112-3}$

Häder D-P (1997) Penetration and effects of solar UV-B on phytoplankton and macroalgae. Plant Ecol 128: 4-13. DOI: $\underline{10.1007 / 978-94-011-5718-6 \_1}$
Häder D-P, Kumar HD, Smith RC and Worrest RC (2007) Effects of solar UV radiation on aquatic ecosystems and interactions with climate change. Photochem Photobiol Sci 6: 267-285. DOI: 10.1039/b700020k

Hartmann A, Becker K, Karsten U, Remias D and Ganzera M (2015) Analysis of mycosporine-like amino acids in selected algae and cyanobacteria by hydrophilic interaction liquid chromatography and a novel MAAs from the red alga Catenella repens. Mar Drugs 13: 6291-6305. DOI: 10.3390/md13106291

Hartmann A, Holzinger A, Ganzera M and Karsten U (2016) Prasiolin, a new UV-sunscreen compound in the terrestrial green macroalga Prasiola calophylla (Carmichael ex Greville) Kützing (Trebouxiophyceae, Chlorophyta). Planta 243: 161-169. DOI: $\underline{10.1007 / \mathrm{s} 00425-015-2396-\mathrm{Z}}$

Helbling EW, Barbieri ES, Sinha RP, Villafañe VE and Häder DP (2004) Dynamics of potentially protective compounds in Rhodophyta species from Patagonia (Argentina) exposed to solar radiation. J Photochem Photobiol $B$ 75: 63-71. DOI: 10.1016/j.jphotobiol.2004.05.006

Helbling EW, Menchi CF and Villafañe VE (2002) Bioaccumulation and role of UV-absorbing compounds in two marine crustacean species from Patagonia, Argentina. Photochem Photobiol Sci 1: 820-825. DOI: 10.1039/B206584C

Hofmann DJ and Deshler T (1991) Evidence from balloon measurements for chemical depletion of stratospheric ozone in the Arctic winter of 1989-90. Nature 349: 300-305. DOI: $\underline{10.1038 / 349300 \mathrm{a} 0}$

Hoyer K, Karsten U, Sawall T and Wiencke C (2001) Photoprotective substances in Antarctic macroalgae and their variation with respect to depth distribution, different tissues and developmental stages. Mar Ecol Prog Ser 211: 117-129. DOI: 10.3354/meps211117

Kannaujiya VK, Richa and Sinha RP (2014) Peroxide scavenging potential of ultraviolet-B-absorbing mycosporine-like amino acids isolated from a marine red alga Bryocladia sp. Front Environ Sci 2: 1-6.

Karentz D, Cleaver JE and Mitchell DL (1991a) Cell survival characteristics and molecular responses of Antarctic phytoplankton to ultraviolet-B radiation. J Phycol 27: 326-341. DOI: $10.1111 / \mathrm{j} .0022-3646.1991 .00326 . \mathrm{x}$

Karentz D, Cleaver JE and Mitchell DL (1991b) DNA damage in the Antarctic. Nature 350: 28-28. DOI: $\underline{10.1038 / 350028 \mathrm{~b} 0}$

Karentz D, McEuen FS, Land MC and Dunlap WC (1991c) A survey of mycosporine-like amino acid compounds in Antarctic marine organisms: potential protection from ultraviolet exposure. Mar Biol 108: 157-166. DOI: $\underline{10.1007 / \mathrm{BF} 01313484}$

Karsten U, Sawall T and Wiencke C (1998b) A survey of the distribution of UV-absorbing substances in tropical macroalgae. Phycol Res 46: 271-279. 
Karsten U, Sawall T, Hanelt D, Bischof K, Figueroa FL, FloresMoya A and Wiencke C (1998a) An inventory of UVabsorbing mycosporine-like amino acids in macroalgae from polar to warm-temperate regions. Bot Mar 41: 443-453. DOI: $10.1515 /$ botm.1998.41.1-6.443

Katoch M, Mazmouz R, Chau R, Pearson LA, Pickford R and Neilan BA (2016) Heterologous production of cyanobacterial mycosporine-like amino acids mycosporine-Ornithine and mycosporine-Lysine in Escherichia coli. Appl Environ Microbiol 82(20): 6167-6173. DOI: 10.1128/AEM.01632-16

Kim ST and Sancar A (1995) Photorepair of nonadjacent pyrimidine dimers by DNA photolyase. Photochem Photobiol 61: 171-174. DOI: $\underline{10.1111 / \mathrm{j} .1751-}$ 1097.1995.tb03956.x

Kräbs G, Bischof K, Hanelt D, Karsten U and Wiencke C (2002) Wavelength-dependent induction of UV-absorbing mycosporine-like amino acids in the red alga Chondrus crispus under natural solar radiation. J Exp Mar Biol Ecol 268: 69-82. DOI: 10.1016/S0022-0981(01)00380$\underline{X}$

Lesser MP (2008) Effects of ultraviolet radiation on productivity and nitrogen fixation in the cyanobacterium, Anabaena sp. (Newton's strain). Hydrobiologia 598: 1-9. DOI: $\underline{10.1007 / \mathrm{s} 10750-007-9126-\mathrm{X}}$

Lubin D and Jensen EH (1995) Effects of clouds and stratospheric ozone depletion on ultraviolet radiation trends. Nature 377: 710-713. DOI: 10.1038/377710a0

Lüning K (1985) Meeresbotanik: verbreitung, ökophysiologie und nutzung der marinenmakroalgen. ThiemeVerlag, Stuttgart.

Madronich S, McKenzie R, Bjorn R and Caldwell M (1998) Changes in biologically active ultraviolet radiation reaching the Earth's surface. J Photochem Photobiol B:Biol 46: 5-19. DOI: 10.1016/S1011-1344(98)00182$\underline{1}$

Middleton EM and Teramura AH (1994) Understanding photosynthesis, pigment and growth responses induced by UV-B and UV-A irradiances. Photochem Photobiol 60: 38-45. DOI: 10.1111/j.1751-1097.1994.tb03940.x

Misonou T, Saitoh J, Oshiba S, Tokitomo Y, Maegawa M, Inoue Y, Hori H and Sakurai T (2003) UV-absorbing substance in the red alga Porphyra yezoensis (Bangiales, Rhodophyta) block thymine dimer production. Mar Biotechnol 5(2): 194-200. DOI: $\underline{10.1007 / \mathrm{s} 10126-002-0065-2}$

Nakamura H, Kobayashi J and Hirata Y (1982) Separation of mycosporine-like amino acids in marine organisms using reverse-phase high performance liquid chromatography. J Chromatogr 250: 113-118. DOI: 10.1016/S0021-9673(00)95219-1

Oren A and Gunde-Cimerman N (2007) Mycosporines and mycosporine-like amino acids: UV protectants or multipurpose secondary metabolites? FEMS Microbiol Lett 269: 1-10. DOI: $10.1111 /$ j.15746968.2007.00650.x
Oyamada C, Kaneniwa M, Ebitani K, Murata M and Ishihara K (2008) Mycosporine-like amino acids extracted from Scallop (Patinopecten yessoensis) ovaries: UV Protection and growth stimulation activities on human cells. Mar Biotech 10: 141-150. DOI: $10.1007 / \mathrm{s} 10126-$ $\underline{007-9043-\mathrm{Z}}$

Portwich A and Garcia-Pichel F (1999) Ultraviolet and osmotic stresses induce and regulate the synthesis of mycosporines in the cyanobacterium Chlorogloeopsis PCC 6912. Arch Microbiol 172: 87-192. DOI: $10.1007 / \mathrm{s} 002030050759$

Rajneesh, Singh SP, Pathak J and Sinha RP (2016) Cyanobacterial factories for the production of green energy and value-added products: an integrated approach for economic viability. Renew Sustainable Energy Rev DOI: 10.1016/j.rser.2016.11.110

Rastogi RP and Sinha RP (2009) Biotechnological and industrial significance of cyanobacterial secondary metabolites. Biotechnol Adv 27(4): 521-539. DOI: 10.1016/j.biotechadv.2009.04.009

Ravishankara AR, Daniel JS and Portmann RW (2009) Nitrous oxide $\left(\mathrm{N}_{2} \mathrm{O}\right)$ : the dominant ozone-depleting substance emitted in the 21st century. Science 326: 123-125. DOI: $\underline{10.1126 / \text { science. } 1176985}$

Rezanka T, Temina M, Tolstikov AG and Dembitsky VM (2004) Natural microbial UV radiation filters-mycosporinelike amino acids. Folia Microbiol 49: 339-352. DOI: 10.1007/BF03354663

Richa and Sinha RP (2015) Biochemical characterization of sunscreening mycosporine-like amino acids from two Nostoc species inhabiting diverse habitats. Protoplasma 252: 199-208. DOI: 10.1007/s00709-014$\underline{0674-4}$

Richa, Sinha RP and Häder D-P (2016) Effects of global change, including $\mathrm{UV}$ and $\mathrm{UV}$ screening compounds. In: Borowitzka MA, Beardall J and Raven JA (Eds) The Physiology of Microalgae. Springer International Publishing, Switzerland, 373-409. DOI: $\underline{10.1007 / 978-}$ 3-319-24945-2_17

Rinalducci S, Hideg, Vass I and Zolla L (2006) Effect of moderate UV-B irradiation on Synechocystis PCC 6803 biliproteins. Biochem Biophys Res Commun 341: $1105-$ 1112. DOI: $10.1016 / j . b b r c .2006 .01 .070$

Sahoo A, Sarkar S, Singh RP, Kafatos M and Summers ME (2005) Declining trend of total ozone column over the northern parts of India. Int J Remote Sens 26: 33-40. DOI: $10.1080 / 01431160500076467$

Schmid D, Schürch C and Zülli F (2006) Mycosporine-like amino acids from red algae protect against premature skin-aging. Eur Cosmet 9: 1-4.

Schmidt EC, dos Santos R, Horta PA, Maraschin M and Bouzon ZL (2010a) Effects of UVB radiation on the agarophyte Gracilaria domingensis (Rhodophyta, Gracilariales): changes in cell organization, growth and photosynthetic performance. Micron 41: 919-930. DOI: 10.1016/j.micron.2010.07.010 
Schmidt EC, Maraschin M and Bouzon ZL (2010b) Effect of UVB radiation on the carragenophyte Kappaphycus alvarezii (Rhodophyta, Gigartinales) changes in ultrastructure, growth, and photosynthetic pigments. Hydrobiologia 649: 171-182. DOI: 10.1007/s10750$\underline{010-0243-6}$

Shick JM and Dunlap WC (2002) Mycosporine-like amino acids and related gadusols: biosynthesis, accumulation, and UV-protective functions in aquatic organisms. Annu Rev Physiol 64: 223-262. DOI: 10.1146/annurev.physiol.64.081501.155802

Singh G, Babele PK, Sinha RP, Tyagi MB and Kumar A (2013) Enymatic and non-enzymatic defense mechanisms against ultraviolet-B radiation in two Anabaena species. Process Biochem 48: 796-802. DOI: 10.1016/j.procbio.2013.04.022

Singh SP, Kumari S, Rastogi RP, Singh KL and Sinha RP (2008) Mycosporine-like amino acids (MAAs): chemical structure, biosynthesis and significance as UVabsorbing/screening compounds. Ind J Exp Biol 46: 717.

Sinha RP, Dautz M and Häder D-P (2001) A simple and efficient method for the quantitative analysis of thymine dimers in cyanobacteria, phytoplankton and macroalgae. Acta Protozool 40: 187-195.

Sinha RP, Klisch M and Häder D-P (1999) Induction of a mycosporine-like amino acid (MAA) in the rice-field cyanobacterium Anabaena sp. by UV irradiation. $J$ Photochem Photobiol B: Biol 52: 59-64. DOI: 10.1016/s1011-1344(99)00103-7

Sinha RP, Klisch M, Gröniger A and Häder D-P (2000) Mycosporine-like amino acids in the marine red alga Gracilaria cornea-effects of UV and heat. Environ Exp Bot 43: 33-43. DOI: 10.1016/S0098-8472(99)00043-X

Sinha RP, Klisch M, Gröniger A and Häder D-P (1998) Ultraviolet absorbing/screening substances in cyanobacteria, phytoplankton and macroalgae. $J$ Photochem Photobiol B 47: 83-94. DOI: $\underline{10.1016 / \mathrm{S} 1011-1344(98) 00198-5}$
Sinha RP, Kumari S and Rastogi RP (2008) Impacts of ultraviolet-B radiation on cyanobacteria: photoprotection and repair. J Sci Res 52: 125-142.

Sinha RP, Singh SP and Häder D-P (2007) Database on mycosporines and mycosporine-like amino acids (MAAs) in fungi, cyanobacteria, macroalgae, phytoplankton and animals. J Photochem Photobiol B 89: 29-35. DOI: $10.1016 /$ j.jphotobiol.2007.07.006

Sinha RP and Häder D-P (1996) Photobiology and ecophysiology of rice field cyanobacteria. Photochem Photobiol 64: 887-896. DOI: $10.1111 /$ j.1751-1097.1996.tb01852.x

Smith RC, Prézelin BB, Baker KS, Bidigare RR, Boucher NP, Coley T, Karentz D, MacIntyre S, Matlick HA, Menzies D, Ondrusek M, Wan Z and Waters KJ (1992) Ozone depletion: ultraviolet radiation and phytoplankton biology in Antarctic waters. Science 255: 952-959. DOI: $10.1126 /$ science. 1546292

Van De Poll WH, Bischof K and Buma AGJ (2003) Habitat related variation in UV tolerance of tropical marine red macrophytes is not temperature dependent. Physiol Plant 118: $\quad 74-83$. DOI: $\underline{10.1034 / j .1399-}$ 3054.2003.00090.x

Vincent WF and Neale PJ (2000) Mechanisms of UV damage to aquatic organisms. In: de Mora SJ, Demers $\mathrm{S}$ and Vernet M (Eds) The effects of UV radiation on marine ecosystems. Cambridge University Press, Cambridge, 149-176. DOI: $10.1017 /$ cbo9780511535444.007

Vincent WF and Roy S (1993) Solar ultraviolet-B radiation and aquatic primary production: damage, protection, and recovery. Environ Rev 1: 1-12. DOI: 10.1139/a93-001

Whitehead K and Hedges JI (2005) Photodegradation and photosensitization of mycosporine-like amino acids. $J$ Photochem Photobiol B:Biol 80: 115-121. DOI: 10.1016/j.jphotobiol.2005.03.008

Williamson CE (1995) What role does UV-B radiation play in freshwater ecosystems? Limnol Oceanogr 40: 386-392.

Wu JJW, Chalker BE and Rideout JA (1997) Two new UVabsorbing compounds from Stylophora pistillata: sulfate esters of mycosporine-like amino acids. Tetrahedron Lett 38(14): 2525-2526. DOI: 10.1016/S0040-4039(97)00391-2 